\title{
BACKSCATTERING FROM THE NEAR-SURFACE LAYER OF THAWED/FROZEN SOILS OF ALASKA FROM SENTINEL 1 RADAR DATA
}

\section{Natali V. Rodionova}

Kotelnikov Institute of Radioengineering and Electronics of RAS, Fryazino Branch, http://fire. relarn.ru

Fryazino 141190, Moscow Region, Russian Federation

rnv@ire.rssi.ru

Abstract. This paper considers the question of determining frozen/unfrozen status of $5 \mathrm{~cm}$ topsoil layer for seven ground stations in Alaska with latitude from $65^{\circ}$ to $70^{\circ} \mathrm{N}$ by using radar Sentinel 1 C-band data for the period 2016-2017. Determine the status of frozen soil was carried out by two ways: using only radar data with finding the backscatter coefficient threshold, when the temperature in the upper soil layer falls below $0{ }^{\circ} \mathrm{C}$, and by using both radar data and ground-based measurements of soil temperature. In the latter case, the correlation between the backscattering coefficient and the soil temperature measured at $5 \mathrm{~cm}$ below the soil surface was calculated. Regression models were developed and radar backscatter thresholds for frozen soil were found. Local frozen/unfrozen soil maps were created. The comparison of threshold values obtained by two ways showed their closeness, which tends to decrease with decreasing correlation between radar and ground data. Linear regression between radar backscatter threshold and the area latitude have been received.

Keywords: C-band radar data, soil temperature, frozen/unfrozen soil, backscattering coefficient, Spearman's correlation coefficient

UDC 528.854, 528.88

Bibliography - 12 references

Received 13.03.2019, attached 29.03.2019

RENSIT, 2019, 11(1):21-30

DOI: $10.17725 /$ rensit.2019.11.021

Contents

1. INTRODUCTION (21)

2. Ground data (22)

3. The input S1 radar data (23)

4. Determination of frozen/thawed SOIL STATE FROM S1 RADAR DATA (24)

5. Determination of the state of FROZEN SOIL BY CORRELATION BETWEEN RADAR AND GROUND DATA (27)

6. Conclusion (28)

REFERENCES (29)

\section{INTRODUCTION}

Remote sensing offers promising methods for monitoring the near-surface state of frozen/ thawed soils on a wide geographical scale [1,
2]. The use of radiometers is limited to very large areas due to the low spatial resolution. Unlike IR and microwave radiometers, SAR systems can provide information at high spatial resolution about the dynamic state of the soil regardless of the cloud and the day time. The radar signal is mainly dependent on the soil dielectric permittivity (DP), which is directly related to the water and ice content, and on surface roughness and vegetation cover.

Active sensors distinguish frozen soil (FS) by changing the content of liquid water in the soil. These changes are associated with the values of the DP of soil [3]. The average 
value of dry soil DP is about 2-3, while liquid water 80 . DP soil grows in proportion to the volume content of liquid water in it. In critical winter conditions, most of the water in the soil freezes, which leads to a significant decrease in the average value of the soil DP. Frozen water has an ice value of 3.2 DP, which is similar to dry soil DP [4]. The reverse process occurs in the spring, when the ice in the soil melts, which leads to an increase in the backscattering coefficient by several decibels [5].

Soil properties (structure, texture, drainage) affect the water content in the soil and on the dynamics of its freezing process. Mineralized soils freeze faster and to a greater depth than organic soils due to their less ability to store water [5]. The same situation exists between sandy and clay soils.

The object of the study was FS in 7 ground stations in Alaska with the latitude of the place from $65^{\circ} \mathrm{N}$ to $70^{\circ} \mathrm{N}$, where soil parameters are in free access by International soil moisture network (ISMN) [6].

Radar Sentinel 1 (S1) C-band IW (interferometric wide swath) mode, $\mathrm{VV}+\mathrm{VH}$ polarizations, $20 \mathrm{~m}$ spatial resolution data for the period 2016-2017 were used in this investigation.

The aim of the work is the distinction between thawed/frozen soils in the upper

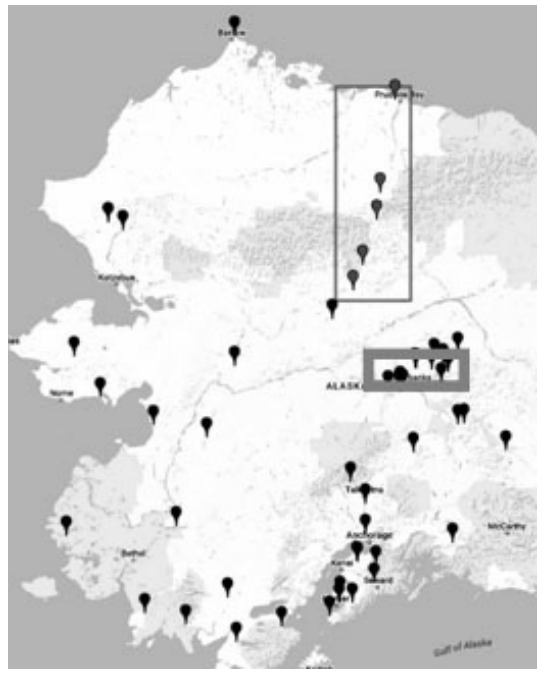

Fig. 1. The location of the considered ground stations in Alaska.

5-cm layer, to find the connection radar backscatter coefficient and the temperature of the upper soil layer; and also to build local maps of frozen/thawed soils using only radar data or radar data together with ground information.

\section{GROUND DATA}

The work used ground measurements of soil parameters (temperature and humidity at depths of 5, 20 and $51 \mathrm{~cm}$ ) and air temperature, which are free available in website of the International soil moisture network (https://ismn.geo.tuwien.ac.at/). Seven stations in Alaska were selected for which the time period of ground-based measurements coincided with available Sentinel 1 radar information. The location of

Information about Alaska ground stations (according to ISMN)

\begin{tabular}{|l|c|c|c|}
\hline Station name & $\begin{array}{c}\text { Latitude, } \\
\text { N deg }\end{array}$ & $\begin{array}{c}\text { Longitude, } \\
\text { W deg. }\end{array}$ & $\begin{array}{c}\text { Soil texture } \\
\text { on the depth 0-30 cm, \% }\end{array}$ \\
\hline Prudhoe Bay & 70.27 & -148.57 & silt -48, sand-34, clay- 18 \\
\hline Imnaviat Creek & 68.62 & -149.3 & sand-73, silt -18, clay- 9 \\
\hline Atigun Pass & 68.13 & -149.48 & sand-73, silt -18, clay- 9 \\
\hline Coldfoot & 67.25 & -150.18 & silt - 48, sand-34, clay- 18 \\
\hline Gobblers Knob & 66.75 & -150.67 & sand-40, silt - 39, clay- 21 \\
\hline Eagle Summit & 65.49 & -145.61 & sand-40, silt - 39, clay- 21 \\
\hline Upper Nome Creek & 65.37 & -146.59 & sand-40, silt - 39, clay- 21 \\
\hline
\end{tabular}




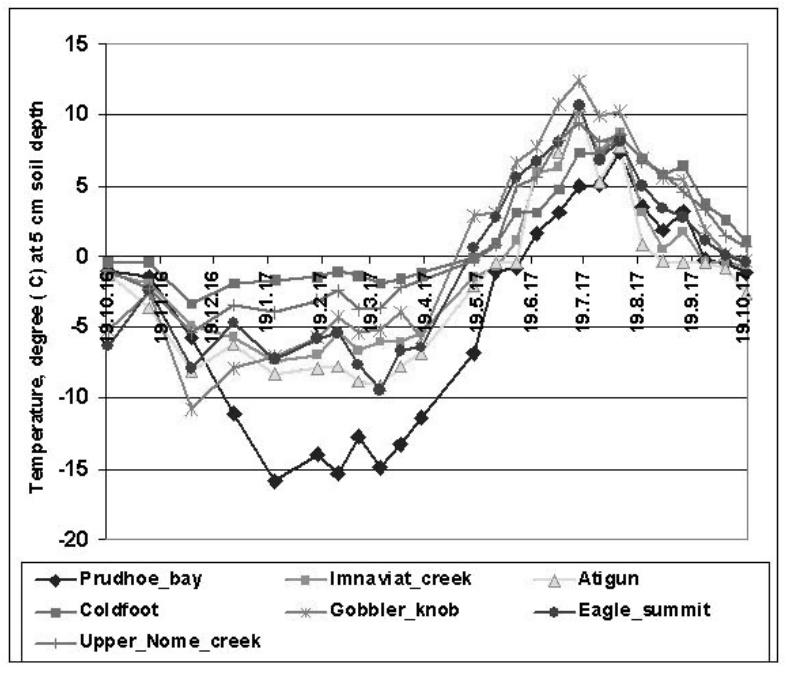

(a)

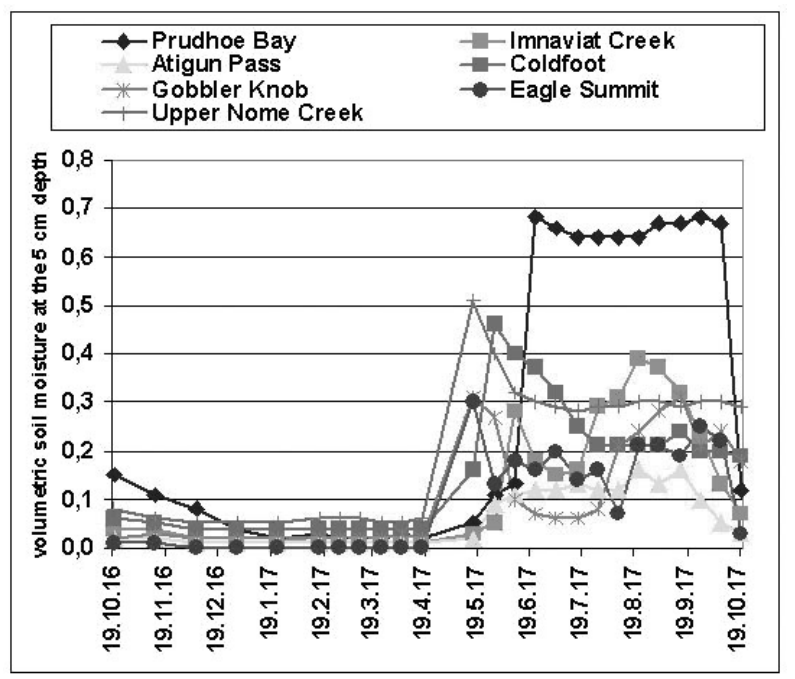

(b)

Fig. 2. Graphs of ground measurements of temperature (a) and volumetric soil moisture at a depth of $5 \mathrm{~cm}$ (b) in Alaska stations for the period 19.10.16-20.10.17 by ISMN data.

the stations is shown in Fig. 1. They are from north to south: Prudhoe Bay, Imnaviat Creek, Atigun Pass, Coldfoot, Gobblers Knob (the five stations marked by top rectangle), Eagle Summit and Upper Nome Creek (stations highlighted in bottom rectangle).

Information about Alaska ground stations is given in Table 1.

The graphs of ground-based measurements of temperature (a) and volumetric soil moisture at a depth of 5 $\mathrm{cm}$ (b) for stations in Alaska for the period 19.10.16 - 20.10.17 are shown in Fig. 2. Both values (soil temperature and humidity) are taken from the ISMN ground measurement database at the time of the site survey by Sentinel 1 radar. It should be noted that for winter time information about soil moisture is not reliable [6].

It follows from Fig. 2 that the lowest soil temperatures at a depth of $5 \mathrm{~cm}$ are for the Prudhoe Bay station- the northernmost of the stations under consideration. The highest temperatures in winter are for Coldfoot and Upper Name Creek stations. In the latter case, this is expected, since Upper Nome Creek is the southernmost of the stations under consideration. For Coldfoot, this is probably due to the height of the snow cover. But, as shown by the graph in Fig. 3, the snow depth for these two stations is almost the same.

\section{THE INPUT S1 RADAR DATA}

In this work, we used Sentinel 1 C-band radar data IW (interferometric wide swath) mode with two polarizations $(\mathrm{VV}+\mathrm{VH})$ and a spatial resolution of $10 \mathrm{~m}$. The $\mathrm{S} 1$ images were processed by a program S1Toolbox and later SNAP [7]. Pre-processing of the data

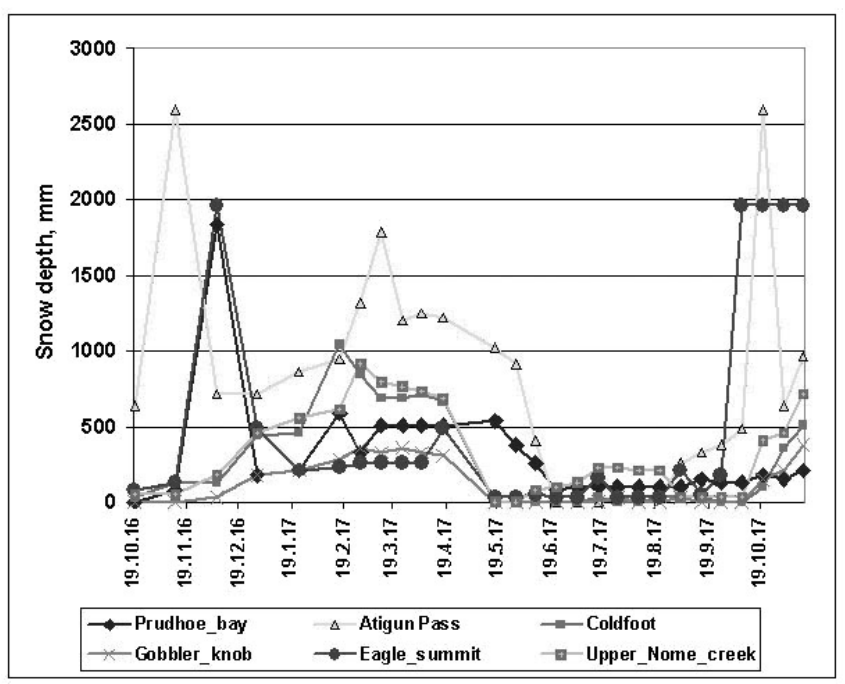

Fig. 3. Snow depth in mm for Alaska ground stations (ISMN data). 
Table 2

Information on S1 radar data used

\begin{tabular}{|l|c|c|c|c|}
\hline Station name & $\begin{array}{c}\text { Number of S1 } \\
\text { processed images }\end{array}$ & View angle & $\begin{array}{c}\text { Radar survey time } \\
\text { period used }\end{array}$ & Number points in profile \\
\hline Prudhoe Bay & 28 & $33^{\circ}$ & $19.10 .16-25.11 .17$ & $\sim 10$ \\
\hline Imnaviat Creek & 28 & $41^{\circ}$ & $21.10 .16-27.11 .17$ & $\sim 10$ \\
\hline Atigun Pass & 25 & $37^{\circ}$ & $31.10 .16-7.11 .17$ & $\sim 10$ \\
\hline Coldfoot & 24 & $42^{\circ}$ & $14.11 .16-27.11 .17$ & $\sim 10$ \\
\hline Gobblers Knob & 23 & $43^{\circ}$ & $14.11 .16-27.11 .17$ & $\sim 10$ \\
\hline Eagle Summit & 28 & $40^{\circ}$ & $23.10 .16-29.11 .17$ & $\sim 15$ \\
\hline Upper Nome Creek & 28 & $40^{\circ}$ & $23.10 .16-29.11 .17$ & $\sim 15$ \\
\hline
\end{tabular}

included selection of the fragment with the study area and radiometric calibration.

Table 2 shows the data for each station by the number of processed survey sessions, viewing angle, time period of survey and the number of points in profile.

\section{DETERMINATION OF FROZEN/ THAWED SOIL STATE FROM S1 RADAR DATA}

The depth of penetration of the e/ $\mathrm{m}$ wave into the soil is determined by the equation $\delta p=\lambda \sqrt{\varepsilon^{\prime}} /\left(2 \pi \varepsilon^{\prime \prime}\right)$, where $\lambda$ - the wavelength, $\varepsilon=\varepsilon^{\prime}+i \varepsilon^{\prime \prime}-$ the dielectric permeability of the soil. For S1 the wavelength is $5.4 \mathrm{~cm}$. In the case of frozen soil with $\varepsilon^{\prime} \approx 5.5$ and $0.1 \leq \varepsilon^{\prime \prime} \leq 0.5$ we get a penetration depth $4 \leq \delta p \leq 20 \mathrm{~cm}$.

The method of identification of thawed/ frozen soil state is based on a 3-5 dB drop in during the transition to the state $[1,2]$.

Using the time series S1, we determine the date of the beginning of freezing/ thawing of the soil by strong differences of $\sigma^{0}$ and further stable low/high values of $\sigma^{0}$. Fig. 4 shows graphs of the difference in the absolute value of $\sigma^{0} \mathrm{VV}$ polarization in $\mathrm{dB}$ for neighboring radar imagery dates. Two peaks allow to determine the date of beginning soil to freeze and thaw. For the Prudhoe Bay station, the first maximum is $2.69 \mathrm{~dB}$. This is abs $(-11.53+14.22)$ $[\mathrm{dB}]=\operatorname{abs}\left(\sigma_{29.5 .2017}^{0}-\sigma_{17.5 .2017}^{0}\right)[\mathrm{dB}]-$ these are the dates to begin soil thawing. The second maximum determines the date of beginning soil to freeze. Maximum equals $1.69 \mathrm{~dB}$. This is $\operatorname{abs}(-16.36+14.67)[\mathrm{dB}]=$ abs $\left(\sigma_{20.10 .2017}^{0}-\sigma_{8.10 .2017}^{0}\right)[\mathrm{dB}]$ is the freezing of soil at a $5 \mathrm{~cm}$ layer. For Coldfoot ground station, the difference in soil freezing values is about $3.9 \mathrm{~dB}=\operatorname{abs}\left(\sigma_{10.10 .2017}^{0}-\sigma_{28.09 .2017}^{0}\right)$. When determining the date of thawing of the soil there are difficulties with finding the appropriate maximum. It should be noted that the difficulty to determine maxima increases when the latitude is shifted to the South.

Another way to determine the state of FS only from radar data without using ground measurements is shown in the paper [8]. These authors, similar to [9], characterize the soil cover state by the surface state factor (SSF):

$$
S S F=\frac{1}{2}+\frac{\sigma^{0}(t)-\sigma_{\text {sum }}^{0}}{\sigma_{\text {sum }}^{0}-\sigma_{\text {win }}^{0}},
$$

where $\sigma_{\text {sum }}^{0}$ and $\sigma_{\text {win }}^{0}$ are the mean values of radar backscattering coefficient in summer and winter, respectively, $\sigma^{0}(t)$ is the running value of radar backscattering coefficient, and $t$ is time.

The authors [8] argue that the seasonal SSF variations are highly correlated with the 

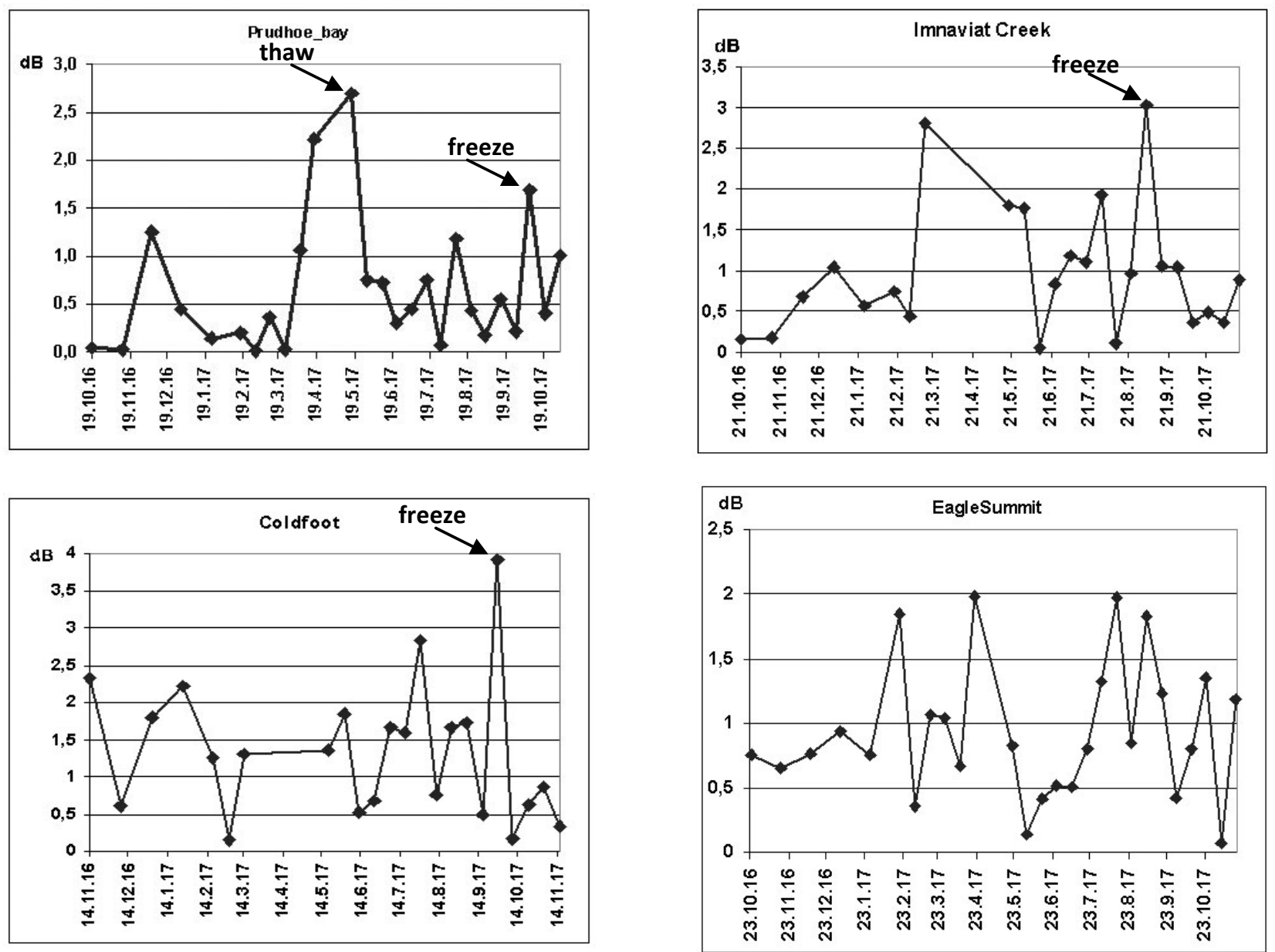

Fig. 4. Graphs of the difference between $\left|\sigma^{0}\right| V V$ polarization for the neighboring radar imagery dates.

seasonal variations of the soil temperature, taking negative values at soil temperatures below $0^{\circ} \mathrm{C}$. Consequently, a $5-\mathrm{cm}$ topsoil layer can be classified as frozen when the SSF, measured by radar, takes a negative value. SSF VV polarization graph for Prudhoe bay station is shown in Fig. 5.

According to the equation (1) it turns out that the intersection of the value SSF $=0$ occurs for the same value, but for different times $t$, i.e. the value $\sigma^{0}$ is the same for both the freezing point and the thawing point of the $5-\mathrm{cm}$ topsoil layer. And this value can be determined for each place, knowing $\sigma_{\text {sum }}^{0}$ and $\sigma_{\text {win }}^{0}$. Let's call this value $\sigma^{0}$ as $\sigma_{t h r}^{0}$. The $\sigma_{t h r}^{0}$ values calculated by the formula (1) for stations in Alaska under consideration are given in Table 3.
The authors [8] noted a strong variability of SSF depending on the latitude. We use the data from table 3 for four stations Imnaviat Creek, Coldfoot, Eagle Summit, Upper Nome Creek to define a relationship $\sigma_{t h r}^{0}$ with

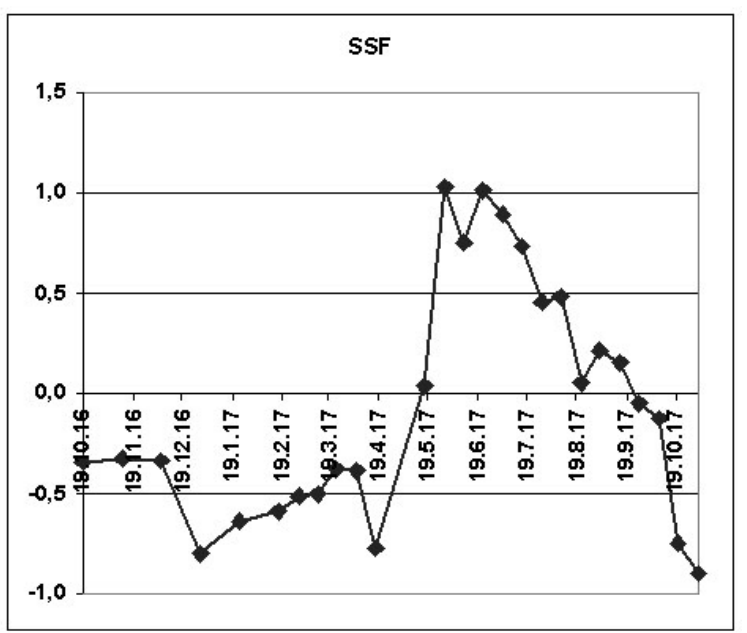

Fig. 5. SSF VV polarization for Prudhoe Bay. 
Table 3.

$\sigma_{t h r}^{0}$ values under SSF $=0$.

\begin{tabular}{|c|c|c|c|c|c|c|c|}
\hline $\begin{array}{c}\text { Ground } \\
\text { station }\end{array}$ & $\begin{array}{c}\text { Prudhoe } \\
\text { Bay }\end{array}$ & $\begin{array}{c}\text { Imnaviat } \\
\text { Creek }\end{array}$ & $\begin{array}{c}\text { Atigun } \\
\text { Pass }\end{array}$ & Coldfoot & $\begin{array}{c}\text { Gobblers } \\
\text { Knob }\end{array}$ & $\begin{array}{c}\text { Eagle } \\
\text { Summit }\end{array}$ & $\begin{array}{c}\text { Upper Nome } \\
\text { Creek }\end{array}$ \\
\hline$\sigma_{t h r}^{0}[\mathrm{~dB}]$ & -14.35 & -17.56 & -12.1 & -14.6 & -15.5 & -11.66 & -10.62 \\
\hline
\end{tabular}

the latitude of the place. As a result, in Fig. 6 the obtained regression relation with the coefficient of determination 0.97 is shown, which connects the value $\sigma_{t h r}^{0}[\mathrm{~dB}]$ with the latitude of the place.

If the air temperature is known, the average summer and winter $\sigma^{0}$ values can be determined using, for example, work [10], where the authors define winter and summer periods as follows: if the air temperature is less than the winter threshold (WT), equal to $-3^{\circ} \mathrm{C}$, the corresponding date is considered as belonging to the winter period. Similarly, the threshold for summer at $+3^{\circ} \mathrm{C}$ is used to determine

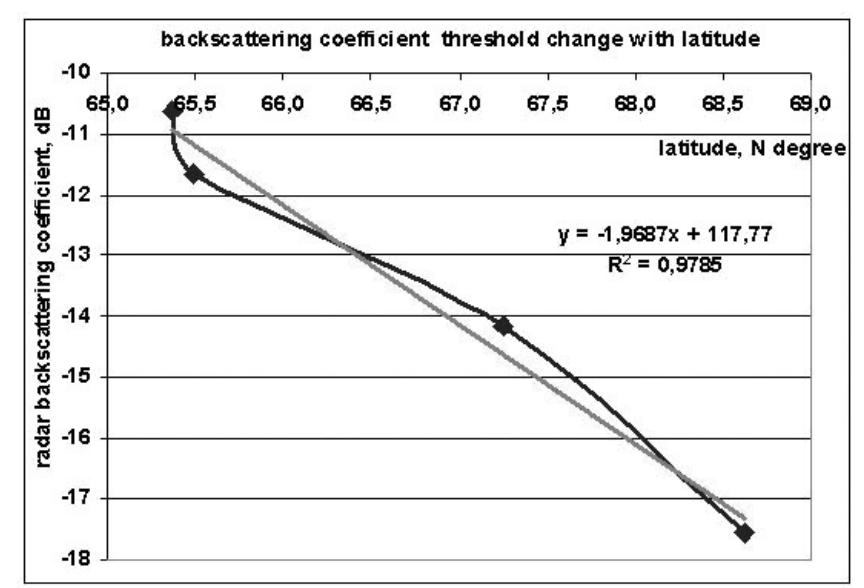

Fig. 6. The $\sigma_{\text {thr }}^{0}$ change with latitude.

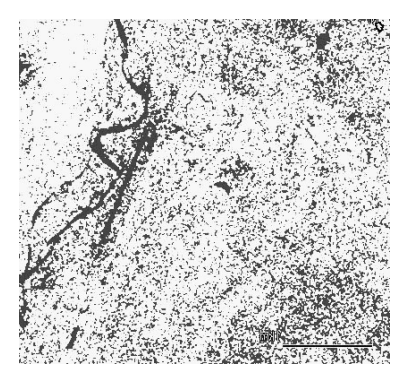

$28 / 09 / 2017$

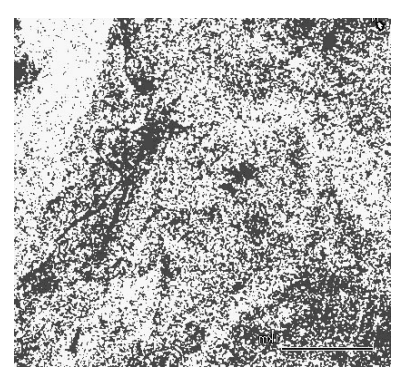

$22 / 10 / 2017$

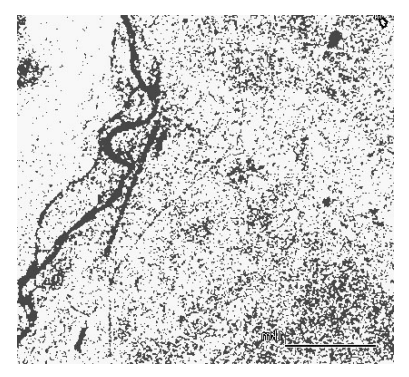

$19 / 05 / 2017$

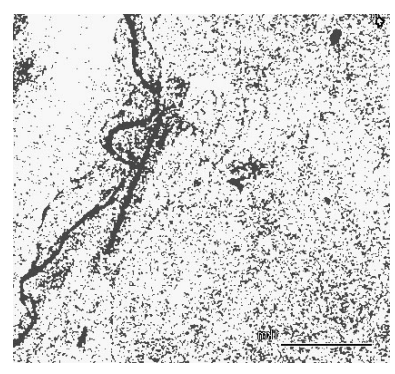

$12 / 06 / 2017$

Fig. 7. Local maps of frozen (dark tone) and unfrozen soil at a $5 \mathrm{~cm}$ top layer for Coldfoot with $\sigma_{\text {thr }}^{0}=-14.16 \mathrm{~dB}$. 


\section{DETERMINATION OF THE} STATE OF FROZEN SOIL BY CORRELATION BETWEEN RADAR AND GROUND DATA

For the first time, a strong correlation between $\sigma^{0}$ and temperature of thawed/frozen soil in $5 \mathrm{~cm}$ top layer was experimentally established by [1, 2] for radar RADARSAT-1 measurements in C-band $\mathrm{HH}$ polarization. Simple linear regression showed a positive correlation between $\sigma^{0}$ and soil temperature with different determination coefficients of (DC) depending on the mechanical soil composition. Regression models were obtained to find the threshold that was used to separate frozen and unfrozen soils. This $\sigma_{t h r}^{0}$ is the $\sigma^{0}$ value at which the corresponding soil temperature is below $0^{\circ} \mathrm{C}$. The authors used the empirically obtained temperature dependence of $\sigma^{0}$ to construct a map of thawed and frozen soils on agricultural fields in the area of Quebec (Canada).

The authors of [11] showed the presence of a strong correlation between the co polarization ratio (CR) of backscattered radar scattering cross sections on horizontal and vertical polarizations and the average temperature in the upper soil layer with a thickness of $0.1 \mathrm{~m}$. On the basis of this, the authors [11] proposed to remotely measure the average temperature in the upper soil layer by the measured CR values by ALOS PALSAR full polarimetry data.

In this work, to determine the correlation between $\sigma^{0}$ and soil temperature at a $5 \mathrm{~cm}$ top layer, it was used S1 radar data C-band, VV polarization, and ground information from ISMN [6]. Linear regression model between $T^{\circ}$ in $5 \mathrm{~cm}$ topsoil layer, and the $\sigma^{0}$ can be used to predict $T^{\circ}$ of soil and to construct maps of frozen soils using a threshold value $\sigma_{t h r}^{0}$. The disadvantage here is that with a low coefficient of determination, the accuracy of determining the threshold will also be small.

Table 4 shows the Spearman correlation coefficient between $\sigma^{0}$ and ground measurements of soil temperature at a depths of 5, 20 and $51 \mathrm{~cm}$, as well as air temperature (ISMN).

In Fig. 8 the regression were shown for the stations with high correlation between $\sigma^{0}$ and ground measurements of soil temperature at a depth of $5 \mathrm{~cm}$ : Prudhoe Bay, Imnaviat Creek, Upper Nome Creek and Coldfoot.

Table 4.

Spearman correlation coefficient between $\sigma^{0}$ and ground measurements of air and soil temperature

\begin{tabular}{|c|c|c|c|c|c|c|c|}
\hline & $\begin{array}{l}\text { Prudhoe } \\
\text { Bay }\end{array}$ & Eagle Summit & $\begin{array}{l}\text { Upper Nome } \\
\text { Creek }\end{array}$ & Imnaviat Creek & Atigun Pass & Coldfoot & Gobblers Knob \\
\hline \multicolumn{8}{|c|}{$\mathrm{T}^{\circ}$, air } \\
\hline$\sigma_{v v}^{0}$ & $\rho_{s}=0.71, \mathrm{p}=10^{-6}$ & $\rho_{s}=0.24, \mathrm{p}=0.1$ & $\rho_{s}=0.64, \mathrm{p}=10^{-4}$ & $\rho_{s}=0.8, \mathrm{p}=10^{-6}$ & $\rho_{s}=-0.24, \mathrm{p}=0.12$ & $\rho_{s}=0.58, \mathrm{p}=10^{-3}$ & $\rho_{s}=0.44, \mathrm{p}=0.02$ \\
\hline \multicolumn{8}{|c|}{$\mathrm{T}^{\circ}$, soil $5 \mathrm{~cm}$} \\
\hline$\sigma_{v v}^{0}$ & $\rho_{s}=0.69, \mathrm{p}=10^{-5}$ & $\rho_{s}=0.38, \mathrm{p}=0.02$ & $\rho_{s}=0.78, \mathrm{p}=0$ & $\rho_{s}=0.74, \mathrm{p}=10^{-5}$ & $\rho_{s} \quad 0.37, \mathrm{p}=0.03$ & $\rho_{s}=0.65, \mathrm{p}=10^{-4}$ & $\rho_{s}=0.49, \mathrm{p}=0.01$ \\
\hline \multicolumn{8}{|c|}{$\mathrm{T}^{\circ}$, soil $20 \mathrm{~cm}$} \\
\hline$\sigma_{v v}^{0}$ & $\rho_{s}=0.5, \mathrm{p}=10^{-3}$ & $\rho_{s}=0.36, \mathrm{p}=0.03$ & $\rho_{s}=0.78, \mathrm{p}=0$ & $\rho_{s}=0.73, \mathrm{p}=10^{-5}$ & $\rho_{s}=-0.35, \mathrm{p}=0.04$ & $\rho_{s}=0.56, \mathrm{p}=10^{-3}$ & $\rho_{s}=0.55, \mathrm{p}=0.003$ \\
\hline \multicolumn{8}{|c|}{$\mathrm{T}^{\circ}$, soil $51 \mathrm{~cm}$} \\
\hline$\sigma_{v v}^{0}$ & $\rho_{s}=0.32, \mathrm{p}=0.05$ & $\rho_{s}=0.26, \mathrm{p}=0.08$ & $\rho_{s}=0.74, \mathrm{p}=10^{-5}$ & $\rho_{s}=0.68, \mathrm{p}=10^{-4}$ & $\rho_{s}=-0.38, \mathrm{p}=0.03$ & $\rho_{s}=0.3, \mathrm{p}=0.07$ & $\rho_{s}=0.54, \mathrm{p}=0.003$ \\
\hline
\end{tabular}



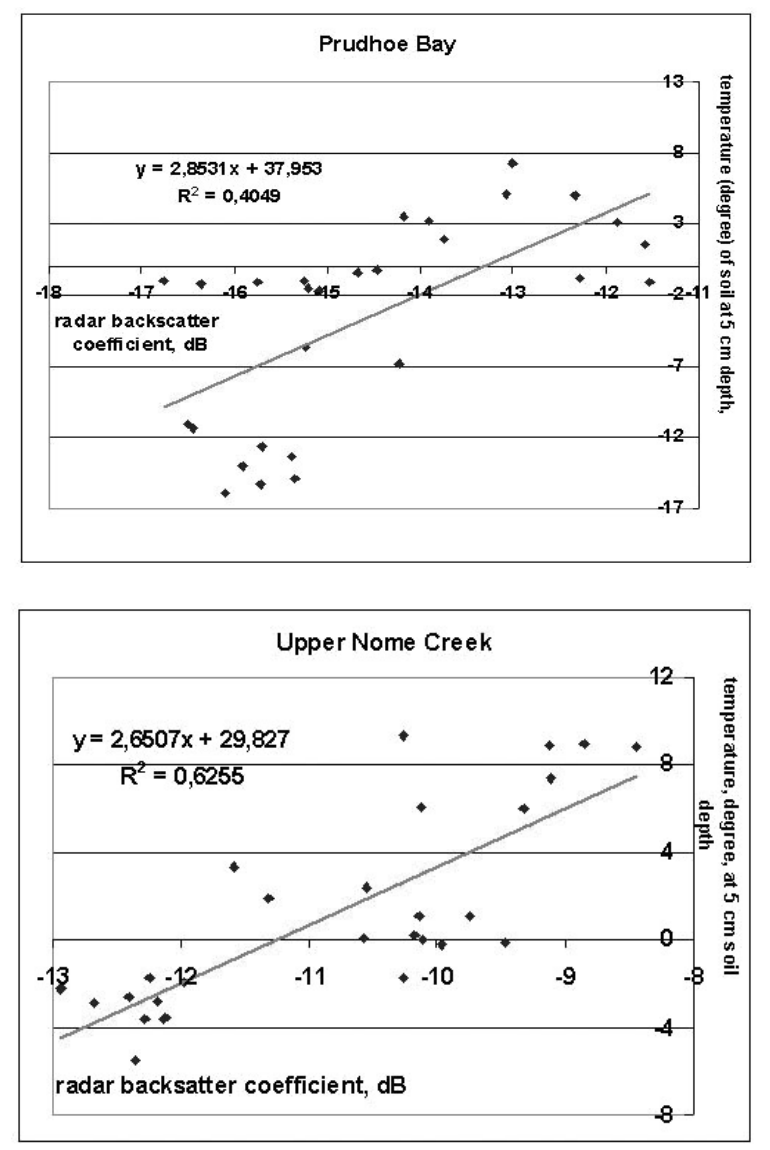
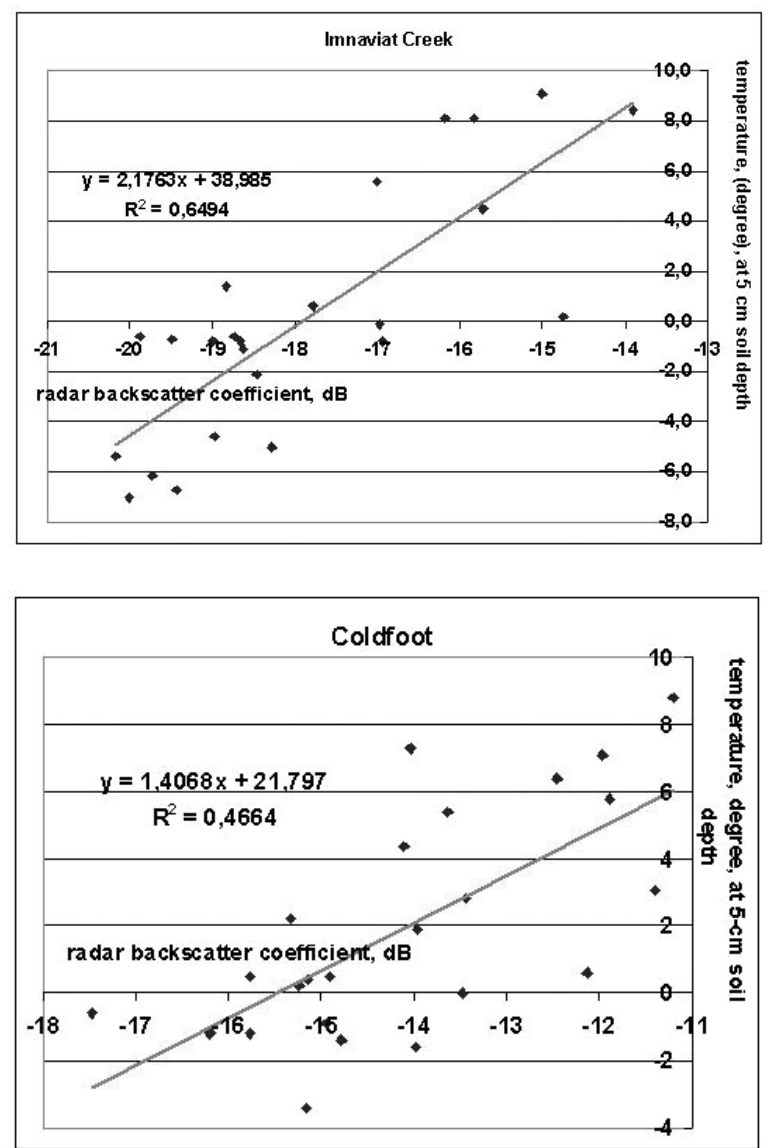

Fig. 8. Regression relations between $\sigma^{0}(d B) V V$ polarization and soil temperature at a depth of $5 \mathrm{~cm}$.

Let us compare the $\sigma_{t h r}^{0}$ values obtained from the regression (Table 5) with those obtained without the use of ground information (Table 3). The difference value is less than $1 \mathrm{~dB}$ with high correlation (Prudhoe Bay, Imnaviat Creek, Upper Nome Creek) and more than $1 \mathrm{~dB}$, with an average correlation (Coldfoot).

It should be noted that the work [12] considered the correlation of S1 radar data with ground measurements of soil temperature for stations in Germany and France, where soil temperatures are only positive. And it is shown that the correlation varies from high to weak, and depends on the granulometric composition of the soil, soil roughness. For frozen soils, this trend continues, namely, the value of determination coefficient $R^{2}$ is greater for stations with a high percentage of sand in the soil. So, the value of $R^{2}=0.65$ obtained for the Imnaviat Creek with $73 \%$ sand content in the soil, and $\mathrm{R}^{2} \approx 0.4$ for stations with $34 \%$ sand content in the soil (Prudhoe Bay, Coldfoot).

\section{CONCLUSION}

The paper deals with the distinction between thawed and frozen soils in the upper $5 \mathrm{~cm}$ layer for seven Alaska ground stations with a latitude from $65^{\circ} \mathrm{N}$ to $70^{\circ} \mathrm{N}$ according to S1 radar data for the period 2016-2017. Determining the status of the FS was carried

Table 5.

The $\sigma_{t h r}^{0}$ value from regression.

\begin{tabular}{|c|c|c|c|c|}
\hline Наземная станция & Prudhoe Bay & Imnaviat Creek & Coldfoot & Upper Nome Creek \\
\hline$\sigma_{t h r}^{0}[\mathrm{~dB}]$ & -13.3 & -17.94 & -15.5 & -11.25 \\
\hline
\end{tabular}


out in two ways: 1) using radar data with finding the threshold values of the backscatter coefficient $\sigma_{t h r}^{0}$, when the temperature in the 5 -cm topsoil layer falls below $0^{\circ} \mathrm{C}$, and 2) the joint use of radar data and groundbased measurements of soil temperature. In the latter case, the correlation between $\sigma^{0}$ and soil temperature at different depths from 5 $\mathrm{cm}$ to $51 \mathrm{~cm}$ is determined. It is shown that the Spearman correlation coefficient is the highest between $\sigma^{0}$ and soil temperature at a depth of $5 \mathrm{~cm}$. In the case of high and moderate correlation, regression models are constructed for the relationship between $\sigma^{0}$ and soil temperature at a depth of $5 \mathrm{~cm}$ for the stations Prudhoe Bay, Imnaviat Creek, Upper Nome Creek and Coldfoot with determination coefficients in the case of linear regression, respectively, $0.4,0.64,0.62$ and 0.46. It is shown that DC increases with the increase of the percentage content of sand in the soil. The found threshold values $\sigma_{t h r}^{0}$ polarization $\mathrm{VV}$ allowed to construct local maps of frozen and thawed soils. A comparison of the $\sigma_{t h r}^{0}$ obtained by the two methods showed the proximity of the values, but the difference between the values increases as the correlation between radar and ground data decreases. The difference value is less than $1 \mathrm{~dB}$ with high correlation (Prudhoe Bay, Imnaviat Creek Upper Nome Creek) and more than $1 \mathrm{~dB}$, with an average correlation (Coldfoot). Linear regression with $R^{2}=0.97$ is obtained for the connection $\sigma_{t h r}^{0} \mathrm{VV}$ polarization with site latitude.

\section{REFERENCES}

1. Khaldoune J, Van Bochove E, Bernier M, Nolin MC. An approach for mapping frozen soil of agricultural land under snow cover using RADARSAT-1 and
RADARSAT-2. Proc. of IGARSS'2008. Boston Mass., 2008, Vol.III 382-385.

2. Khaldoune J, Van Bochove E, Bernier M, Nolin MC. Mapping agricultural frozen soil on the watershed scale using remote sensing data. Appl. Environment. Soil Sci., 2011, Article ID 193237:1-16, doi: 10.1155/2011.193237.

3. Hallikainen MT, Ulaby FT, Dobson MC, El-Rayes MA, Wu LK. Microwave dielectric behavior of wet soil-part 1: empirical models and experimental observations. IEEE Trans. GRS, 1985, 23(1):25-34.

4. Way JB, Zimmermann R, Rignot E, McDonald K, Oren R. Winter and spring thaw as observed with imaging radar at BOREAS. J. Geoph. Res., 1997, 102(24): 29673-29684.

5. Ulaby FT, Moore RK, Fung AK. Microwave Remote Sensing:Active and Passive: Vol. 1. Fundamentals and Radiometry. Artech House, Dedham, Mass, USA, 1982.

6. https://ismn.geo.tuwien.ac.at/.

7. https://sentinel.esa.int/web/sentinel/ toolboxes/sentinel-1.

8. Mironov VL, Muzalevsky KV. Spaceborne radar monitoring of soil freezing/thawing processes in the arctic tundra. Russian Physics Journal, 2013, 55(8). (Russian Original No. 8, August, 2012).

9. Kim Y, Kimball JS, McDonald KC, Glassy J. Developing a global data record of daily landscape freeze/thaw status using satellite passive microwave remote sensing. IEEE Trans. GRS, 2011, 49(3): 949-960.

10. Rautiainen K, Parkkinen T, Lemmetyinen J, Schwank M, Wiesmann A, Ikonen J, Derksen Ch, Davydov S, Davydova A, 
Boike J, Langer M, Drusch M, Pulliainen J. SMOS prototype algorithm for detecting autumn soil freezing. Remote Sensing of Environment, 2016, 180:346-360.

11. Mironov VL, Muzalevskij KV. Kosmicheskij radiolokacionnyj monitoring processov zamerzaniya i ottaivaniya pochvy arkticheskoj tundry [Space radar monitoring of the processes of freezing and thawing of the soil in the Arctic tundra]. Izvestiya vuzov. Fizilka, 2012, 55(8):40-43 (in Russ.).

12. Rodionova NV. Svyaz' radarnyh dannyh Sentinel $1 \mathrm{~s}$ nazemnymi izmereniyami temperatury pochvy [Sentinel 1 data correlation with ground measurements of soil temperature]. Sovremennye problemy distancionnogo zondirovaniya Zemli iz kosmosa, 2017, 14(5):135-148 (in Russ.). 